\title{
Un esbozo de traducción latina de la Reposta ahum papel de Moisés Rafael de Aguilar
}

Pablo Toribio Pérez

Leibniz-Institut für Europäische Geschichte, Mainz

Se ofrece el texto y la traducción castellana del esbozo de traducción latina de la Reposta ahum papel de Moisés Rafael de Aguilar (m. 1679) que llevó a cabo Johann Christoph Wolf (1683-1739). El documento autógrafo de este intento de traducción se conserva en Hamburgo, Staats- und Universitätsbibliothek, Theol. 1831. El texto portugués original es un escrito anticristiano que conoció una considerable difusión en diversos círculos protestantes, antitrinitarios y ateos durante el siglo XVIII. Dicha difusión ha sido estudiada por Martin Mulsow; sin embargo, el texto en sí todavía carece de edición.

Palabras Clave: Neolatín; literatura judía en portugués; polémica judía anticristiana; exégesis bíblica; recepción cristiana de textos judíos; literatura clandestina; Ilustración radical; antitrinitarismo.

A Fragmentary Draft of a Latin Translation of Moses Raphael d'Aguilar's REPOSTA AHUM PAPEL. - This article contains the text and Spanish translation of Johann Christoph Wolf's (1683-1739) fragmentary draft of a Latin translation of portions of Moses Raphael d'Aguilar's (d. 1679) Reposta ahum Papel. Wolf's partial translation is preserved in Hamburg, Staats- und Universitätsbibliothek, Theol. 1831. The original Portuguese text is an anti-Christian work which was well known in a number of Protestant, anti-Trinitarian and atheistic circles during the eighteenth century. Its diffusion has been studied by Martin Mulsow; however, the text itself still lacks an edition.

Keywords: Neo-Latin; Jewish Literature in Portuguese; Jewish anti-Christian Polemics; Biblical Exegesis; Christian Reception of Jewish texts; Clandestine Literature; Radical Enlightenment; Anti-Trinitarianism.

\footnotetext{
" ptoribioperez@gmail.com
} 
En la primera mitad del siglo XVIII se difundió en ciertos círculos intelectuales del norte de Europa un breve tratado portugués anónimo procedente de los Países Bajos con el objeto de probar que Cristo no era el Mesías; en su ataque contra la religión cristiana, el autor argumenta que ésta es contraria a la razón y que no tiene apoyo textual en el Antiguo Testamento. El tratado ocupa treinta folios en la versión de Hamburgo y su íncipit es el siguiente:

Reposta ahum papel, que aqui mandou de França huma pesoa de nossa nação, afirmando quatro pontos fondamentais da religião christiana, a saver: 1, que o Masiah avia de ser Deus e home; 2, que o Masiah he ja vindo; 3, que o cap. 53 de Yesahias trata do seu Masiah; 4, e que avia de cesar a observancia da Ley com a vinda do Masiah ${ }^{1}$.

Los lectores cristianos de la época desconocían el nombre del autor del tratado: Moisés Rafael de Aguilar (m. 1679)², según queda de manifiesto por la copia, acaso autógrafa, que se encuentra en un legajo bajo su nombre en la Biblioteca Ets Haim de Ámsterdam (EH 48 A 11, fols. 231r-256r). Martin Mulsow ha señalado la identidad entre el texto de este manuscrito y el de Hamburgo (SUB, Theol. 1831) ${ }^{3}$. A él se debe asimismo el estudio

${ }^{1}$ Según la copia de Hamburgo, Staats- und Universitätsbibliothek (en lo sucesivo SUB), Theol. 1831, por mi lectura directa en marzo de 2013. Estas páginas se encuadran en los trabajos del grupo de investigación de la Junta de Andalucía «Antonio Tovar» (HUM-173), y son posibles gracias a una beca de investigación del DAAD (Universidad de Rostock) y a una beca post-doctoral del Instituto Leibniz de Historia Europea de Maguncia. Agradezco a Miguel Benítez, a José Manuel Cañas y a los evaluadores anónimos de Sefarad su lectura, correcciones y comentarios.

${ }^{2}$ Sobre Rafael de Aguilar, véase Shlomo Berger, Classical Oratory and the Sephardim of Amsterdam: Rabbi Aguilar's 'Tratado de la Retórica' (Hilversum, 1996). Para su relación con Isaac Orobio de Castro ( $c a$. 1617-1687), véase Yosef KaPLAN, From Christianity to Judaism: The Story of Isaac Orobio de Castro (Oxford, 1989), 110-22.

${ }^{3}$ Para el manuscrito de Ámsterdam, véase Lajb Fuks - Renate Gertrud Fuks-MansFeld, Hebrew and Judaic Manuscripts in Amsterdam Public Collections, II: Catalogue of the Manuscripts of Ets Haim / Livraria Montezinos, Sephardic Community of Amsterdam (Leiden, 1975), 84-86 y 229-230; una mención anterior se halla en Joaquim MeNDES DOS Remedios, Os Judeus portugueses em Amsterdam (Coimbra, 1911), 64-67. Para la relación con el manuscrito de Hamburgo, véase Martin Mulsow, Moderne aus dem Untergrund: Radikale Frühaufklärung in Deutschland 1680-1720 (Hamburg, 2002), 61. Hasta el otoño de 2000 los fondos de la Biblioteca Ets Haim de Ámsterdam se encontraban en préstamo en la Biblioteca Nacional de Israel en Jerusalén. 
de la circulación de este texto portugués en los ámbitos de la «Ilustración radical» alemana ${ }^{4}$ : el hugonote Isaac Jaquelot (1647-1708) trajo consigo a Berlín una copia de los Países Bajos, que después pasó a las manos de su correligionario Mathurin Veyssière de la Croze (1661-1739), bibliotecario real de Prusia; éste a su vez puso el texto en conocimiento del erudito Johann Christoph Wolf (1683-1739), hebraísta, helenista y pastor de Santa Catalina de Hamburgo; a partir de estos dos hombres el tratado vino en conocimiento del sociniano Samuel Crell (1660-1747), que lo usó en su polémica antitrinitaria y fue en buena medida responsable de la amplia difusión del texto en la «Ilustración atea» a partir de la década de 1730.

En la actualidad, Miguel Benítez identifica en su inventario de manuscritos filosóficos clandestinos hasta ocho copias del texto: dos en Jerusalén (hoy en Ámsterdam: la copia mencionada más otra en castellano), dos en Hamburgo (la mencionada y una más), y otras en Dresde, Gotha, Halle y Moscú ${ }^{5}$; a ellas hay que añadir la copia de Leipzig señalada por Mulsow ${ }^{6}$. En total, pues, suman nueve testimonios.

Hasta la fecha ningún filólogo ha emprendiendo la edición del texto ${ }^{7}$. Dicha edición se vería enriquecida por el hecho de que se ha transmitido

\footnotetext{
${ }^{4}$ Mulsow, Moderne aus dem Untergrund, 41-84.

${ }^{5}$ Miguel Benítez, La cara oculta de las luces: Investigaciones sobre los manuscritos filosóficos clandestinos de los siglos XVII y XVIII (Valencia, 2003), 64, ítem R XV. De los manuscritos de Dresde (Sächsische Landesbibliothek, N 75 a), Gotha (Forschungs- und Landesbibliothek, Chart. B 1258), Halle (Universitäts- und Landesbibliothek, Misc. Quart. 20 a), y los dos de Hamburgo (SUB, Theol. 1831; Theol. 1832) quedaba ya constancia en la obra original, Miguel BENÍTEZ, La face cachée des lumières: recherches sur les manuscrits philosophiques clandestins de l'âge classique (Oxford - Paris, 1996), 48. El manuscrito de Moscú (Gosudarstvennii Istoricheskii Musei, F. 342, op. 1, núm. 179) fue señalado por primera vez por Geneviève ARTIGAS-MenANT, «Un nouveau fonds moscovite», La lettre clandestine 7 (1998), 159-166: 161, 165-166. Miguel BENíTEZ, «Manuscrits», La lettre clandestine 6 (1997), 136, llama la atención sobre los dos manuscritos de Ets Haim (EH 48 A 11; EH 48 E 8), entonces en Jerusalén (véase nota 3). En cuanto a la copia castellana (EH 48 E 8), véase la mención anterior de FuKs - Funs-Mansfeld, Hebrew and Judaic Manuscripts, 117.

${ }^{6}$ Leipzig, Universitätsbibliothek, Rep. II 62 aa, según Mulsow, Moderne aus dem Untergrund, 44.

${ }^{7}$ Para un resumen de los contenidos y algunos breves extractos véase Mulsow, Moderne aus dem Untergrund, 62-68; ahí mismo se encuentra también una reproducción fotográfica de Hamburgo, SUB, Theol. 1831, fol. 3r (fol. 1r según la paginación interna del tratado portugués).
} 
en tres lenguas: el portugués, el castellano de una de las dos copias de Ámsterdam, y el latín de las traducciones que acometieron varios lectores. Asimismo se conserva un considerable material epistolar relacionado con el texto, en latín y en francés, que Mulsow cita exhaustivamente.

Veyssière de la Croze fue según todos los indicios el primer traductor al latín del tratado, que describe como $^{8}$ Liber blasphemus contra sanctissimam religionem nostram scriptus Amstelodami a Judaeo Lusitano lingua Lusitana. Opus impium quidem, attamen eruditum ('una obra sin duda impía, pero no obstante erudita'). Seguidamente da él mismo noticia de su traducción latina: Hoc opusculum ferme integrum in linguam Latinam olim transtuleram, sed postea, saniore consilio, ob innumerabiles quae eo continentur blasphemias, absolutam propemodum versionem abolevi ('en otro tiempo traduje casi por completo esta obrita al latín, pero después, con mejor consejo, destruí la traducción, prácticamente terminada, debido a las innumerables blasfemias que contiene').

Sin embargo, según narra Mulsow, pese a su supuesta destrucción, la traducción «casi completa» de Veyssière de la Croze fue conocida por algunos lectores; incluso años más tarde el mismo autor habría emprendido una segunda traducción latina, movido por la insistencia de Samuel Crell. Ninguna de estas traducciones ha sido localizada. Sí se conserva, en cambio, una traducción latina completa atribuida a Samuel Engel (17021784), bibliotecario de Berna, así como un extracto latino conservado en el manuscrito de Gotha (proveniente de Copenhague), que quizás podría deberse al propio Crell ${ }^{9}$, y por último un esbozo de traducción latina debido a Johann Christoph Wolf, que es el objeto de la presente aportación.

La traducción atribuida a Engel se encuentra en el manuscrito de Moscú señalado por Artigas-Menant. Ahora bien, gracias a la información aportada por Mulsow podemos poner lícitamente en duda la autoría de Engel: según consta por su correspondencia (en francés), Engel no se ocupó de la traducción él mismo, sino que encargó a dos personas distintas dos traducciones sucesivas (no especifica a qué lengua): encontró la

\footnotetext{
${ }^{8}$ Hamburgo, SUB, Theol. 1831, fol. 2v.

${ }^{9}$ Véase Mulsow, Moderne aus dem Untergrund, 81-82, donde también se transcribe una parte del extracto.
} 
primera (de Justiniani) «tout à faite fautive», y en consecuencia encargó una segunda a otra persona (Fröhlich), que resultó esta vez «parfaitement en État de faire un pareil Ouvrage» ${ }^{10}$. Pues bien, la traducción latina conservada en el manuscrito de Moscú no parece de hecho muy fiable, según puede inferirse de su íncipit ${ }^{11}:$ Responsio ad codicem calamo exaratum et ad nos directum per Franciscum Huma; en efecto, ahí se convierte el documento «que nos mandó hasta aquí desde Francia una persona» (que aqui mandou de França huma pesoa) en un documento «dirigido a nosotros por Francisco Huma».

\section{El esbozo de traducción de Johann Christoph Wolf: TEXTO Y TRADUCCIÓN}

El manuscrito de Hamburgo, Staats- und Universitätsbibliothek, Theol. 1831 contiene: 1) una carta original dirigida a Veyssière de la Croze por Alphonse des Vignoles (director de la Academia Prusiana de las Ciencias) el 18 de enero de 1710, en la que éste lo anima a publicar su traducción con algunas precauciones y propuestas de modificación ${ }^{12}$; 2) el texto portugués que recibió Veyssière de la Croze de manos de Jacquelot, y que más tarde recibió Wolf de manos del primero; 3) el esbozo de traducción de Johann Christoph Wolf, escrito en un pliego intonso doblado en cuarto menor inserto entre las páginas $8 \mathrm{v}$ y $9 \mathrm{r}$ del texto portugués ${ }^{13}$.

${ }^{10}$ Citado por Mulsow, Moderne aus dem Untergrund, 77.

${ }^{11}$ Según la transcripción de Artigas-Menant, «Un nouveau fonds moscovite», 166.

${ }^{12}$ Esta carta está transcrita y reproducida fotográficamente en Mulsow, Moderne aus dem Untergrund, 51-52.

${ }^{13}$ En el catálogo de manuscritos teológicos de la Biblioteca Estatal y Universitaria de Hamburgo (Nilüfer KRÜGER, Die theologischen Handschriften der Staats- und Universitätsbibliothek Hamburg: 3. Quarthandschriften und kleinere Formate (Cod. theol. 1751-2228): Katalog der Handschriften der Staats- und Universitätsbibliothek Hamburg, Band II [Stuttgart, 1993], 33) no se describe este esbozo de traducción como tal, sino como unas «anotaciones críticas» (kritische Anmerkungen). Del mismo modo se dice que la lengua del tratado es el español y se atribuye a Isaac Orobio de Castro (una atribución que ya los propios Veyssière de la Croze y Wolf habían descartado, aunque la había supuesto Jacquelot, véase Mulsow, Moderne aus dem Untergrund, 60). Dicha atribución se debe verosímilmente a la 
Wolf mantuvo comunicación con Veyssière de la Croze a propósito del texto del judío portugués en dos ocasiones, hacia 1715 y hacia 1725. Es en este segundo momento cuando Mulsow sitúa su intento de traducción, en el contexto del renovado interés de Veyssière de la Croze por el tratado, que a su vez se debía al interés mostrado por Samuel Crell ${ }^{14}$.

El texto de la traducción latina de Wolf es el siguiente ${ }^{15}$ :

[fol. 2r] Responsio ad scriptorem $\{\ldots\}^{16}$ adstruentem quatuor capita religionis christianae fundamentalia, nempe: 1) Messiam esse debuisse Deum et hominem; 2) Messiam jam venisse; 3) caput LIII Jesaiae de Messia suo agere; 4) observationem Legis Mosaicae cum ipso Messiae adventu cessare debuisse.

copia conservada también en Hamburgo, SUB, Theol. 1832, que lleva por título: Judaei Lusitani Antichristus sive Christianae religionis concussio, y en cuyo fol. 1v se lee: autorem ferunt Isacum (sic) Orobio medicum, qui Amstelodami 1687 obiit. Sobre el origen de esta copia, más tardía que la anterior, véase Mulsow, Moderne aus dem Untergrund, 73. En la misma descripción del catálogo (KRÜGER, Die theologischen Handschriften, 33) se remite, para una supuesta versión impresa del tratado portugués, a Giovanni Bernardo De Rossi, Bibliotheca Judaica Antichristiana (Parma, 1800), 82, donde se mencionan los Tria scripta adversus christianam religionem (Gouda, 1687) atribuidos a Isaac Orobio. Esta inferencia procede a su vez de la contraportada del propio manuscrito Theol. 1831, donde se ha anotado: «cf. De Rossi, Bibliotheca Antichristiana, p. 95». Dichos Tria scripta están incluidos en la célebre obra del teólogo remonstrante Philip van Limborch (1633-1712), De veritate religionis christianae amica collatio cum erudito Judaeo (Gouda, 1687) y, como puede comprobarse, no son en ningún caso una traducción latina del tratado que nos ocupa.

${ }^{14}$ Mulsow, Moderne aus dem Untergrund, 59-60 y 71-73. El mismo autor se refiere brevemente a la ocupación de Wolf con el «judío portugués» en Mulsow, «Johann Christoph Wolf (1683-1739) und die Geschichte der verbotenen Bücher in Hamburg», en 500 Jahre Theologie in Hamburg: Hamburg als Zentrum christlicher Theologie und Kultur zwischen Tradition und Zukunft, ed. J. A. STEIger (Berlin, 2005), 81-112: 98-99.

${ }^{15}$ Señalo entre corchetes los folios del cuadernillo (sólo están escritos los fols. 2r, $4 \mathrm{r}$ y $4 \mathrm{v}$ ). El signo $\{\ldots\}$ indica los espacios dejados en blanco por Wolf, que se ajustan en cada caso a la extensión de los fragmentos de texto portugués que quedan sin traducir, quizás porque le resultaron ininteligibles. Por lo demás, he respetado los párrafos, pero he normalizado la puntuación y el uso de mayúsculas y minúsculas; asimismo he regularizado el uso de $u$ y $v$, así como de $i$ y $j$, según los usos editoriales habituales para el latín de la época; los subrayados que en el original indican cita literal o título de libro se reproducen mediante comillas o letra cursiva respectivamente.

${ }^{16}$ Queda en blanco el espacio de algo más de una línea. 


\section{CAPUT I}

Continet Prologum, quo ostenditur potissimum ${ }^{17}$ fundamenta religionis christianae contradicere rectae rationi et Scripturae Sacrae.

Extat scriptum quoddam, quod aliquot fundamenta religionis christianae adserere conatur, cujus ${ }^{18}$ confutationem ingrediar. Ante vero quam initium operis faciam, sequentia praemonenda censui. $\{\ldots\}^{19}$

\section{[fol. 4r] CAPUT II}

Refutat argumenta, quae scriptor affert, probaturus Messiam esse Deum et hominem, simulque veritatem confirmat et illustrat.

Postquam in superioribus veritatem tum rationis praesidiis tum testimoniis Scripturae Sacrae superstruximus, jam ad examen argumentorum progredimur, quibus pro contraria parte scriptor noster pugnat, ut sic ex contrariis juxta se positis veritas magis elucescat.

Prima ratio, qua utitur ad demonstrandum, Messiam Deum esse et hominem, petita est ex verbis Jesaiae, cap. IX («Puer natus est nobis, filius datus est nobis, et fuit dominium super humero ejus, et vocabit nomen ejus "mirabilem", “consiliarium", "Deum fortem", "Patrem aeternum", "principem pacis"»).

Ad expositionem cujuscumque Scripturae loci instituendam duo semper observanda sunt. Primum est, ut ${ }^{20}$ fundamenta rei, ad quam explicatio accomodanda est, vera sint et firmissima et ut cum doctrina Scripturae Sacrae in aliis locis consentiant. Alterum est, ut verba textus ejusmodi admittant. Quod ad prius attinet, jam distinte ostendi, id quod illi affirmant e diametro obstare veritati S. Scripturae, quippe quae contrarium multis in locis testatum facit. Quod ad posterius sequentia nunc in medium adferam. Christiani argumentum suum ita formant: ille, cui nomina haec, nempe «Deus fortis», «Pater aeternus», tribuuntur, est Deus, quia illa nomina Deo tantum competunt; jam vero illa Messiae tribuuntur: ergo Messias est Deus. Enimvero utraque propositio, cum major, tum minor, falsa est. Falsitas prioris

\footnotetext{
${ }^{17}$ Se lee maximam partem antes de corrección.

${ }^{18}$ Se lee $q$ antes de corrección.

${ }^{19}$ Queda en blanco todo el resto de la página.

${ }^{20}$ Se lee quod antes de corrección.
} 
ex eo patet, quod multis rebus $\{\ldots\}^{21}$ nomina illa tribuuntur, quia vel existentia et providentia Dei in ${ }^{22}$ illis singulari modo conspicitur, vel eaedem ${ }^{23}$ nomini divino dedicatae sunt. Ita Genes. XXXIII, 20, legitur «quod Jacobus ibi exstruxerit altare et nomen ejus vocavit "Deus fortis Israel"». At Hieronymus perperam convertit ista: «Et erecto ibi altari, invocavit super illud fortissimum Deum Israel». Hoc enim cum veritate textus $\{\ldots\}^{24}$ Et in Exodo XVII ait: «Et aedificavit Moses altare, et vocavit nomen [fol. 4v] ejus Adonai Nissi». Idem dicitur de civitate Jerusalem, Jerem. XXXIII: «Et hoc est nomen quo vocabit eam: "Jehova justitia nostra"». Idem nomen in eodem propheta, XIII" ${ }^{25}$, in eadem significatione tributum legitur Messiae (XXIII): «Et in diebus ejus salvus erit Jehuda, et Israel secure habitabit. Hoc erit nomen quo vocabit eum: Jehova justitia nostra». In fine prophetiae Ezechielis XLVIII, 35: «Et nomen civitatis usque ad illum diem erit: Jehova ibi».

\section{TRADUCCIÓN}

Respuesta a un escritor $\{\ldots\}$ que establece cuatro puntos fundamentales de la religión cristiana, a saber: 1) que el Mesías había de ser Dios y hombre; 2) que el Mesías ya llegó; 3) que el capítulo LIII de Isaías trata sobre su Mesías; 4) que la observación de la Ley de Moisés había de cesar con la llegada del propio Mesías.

\section{CAPÍTULO I}

Contiene el prólogo, en el que se muestra que más bien los fundamentos de la religión cristiana contradicen la recta razón y la Sagrada Escritura.

Existe cierto escrito que intenta afirmar algunos fundamentos de la religión cristiana, a cuya refutación voy a dar comienzo. Pero antes de empezar mi obra he creído que debo hacer las siguientes consideraciones previas. $\{\ldots\}^{26}$

\footnotetext{
${ }^{21}$ Queda en blanco lo que queda de línea.

${ }^{22}$ Se lee $e x$ antes de corrección.

${ }^{23}$ Se lee in antes de corrección.

${ }^{24}$ Queda en blanco el espacio de algo más de una línea.

${ }^{25}$ Esta indicación debe de ser una errata sin tachar por XXIII.

${ }^{26}$ Sigue la declaración racionalista sobre la que llama la atención MuLsow, Moderne aus dem Untergrund, 64. Comienza así, en mi traducción castellana: 'Puesto que la
} 


\section{CAPÍTULO II}

Refuta los argumentos que aduce el escritor para probar que el Mesías es Dios y hombre, y al mismo tiempo confirma e ilustra la verdad.

Después de que en las páginas anteriores hayamos fundado la verdad tanto en los recursos de la razón como en los testimonios de la Escritura Sagrada, procedemos ahora a examinar los argumentos con los que nuestro escritor lucha por la parte contraria, para que así la verdad brille más a partir del análisis conjunto de los contrarios.

La primera razón de la que se sirve para demostrar que el Mesías es Dios y hombre la extrae de las palabras de Isaías, cap. IX ( «Un niño nos ha nacido, un hijo se nos ha dado, y estuvo el dominio sobre su hombro, y se llamará su nombre "admirable", "consejero", "Dios fuerte", "Padre eterno", "príncipe de la paz"»)".

Para establecer la interpretación de cualquier lugar de la Escritura deben observarse siempre dos cosas. La primera es que los fundamentos de aquello a lo que hay que acomodar la explicación sean verdaderos y muy firmes y que estén en consonancia con la doctrina de la Sagrada Escritura en otros lugares. La segunda es que las palabras del texto admitan una interpretación semejante. En cuanto atañe a lo primero, ya he mostrado claramente que lo que ellos afirman se opone diametralmente a la verdad de la Sagrada Escritura, dado que ésta atestigua lo contrario en muchos lugares. En lo que se refiere a lo segundo aduzco ahora lo siguiente. Los cristianos construyen así su argumento: aquel a quien se atribuyen estos nombres, a saber, «Dios fuerte», «Padre eterno», es Dios, dado que esos nombres sólo corresponden a Dios; sin embargo, ahora se atribuyen al Mesías: por tanto el Mesías es Dios. Pues bien, ambos enunciados, tanto el mayor como el menor, son falsos. La falsedad del primero consta por el hecho de que a muchas cosas $\{\ldots\}$ se les atribuyen esos nombres porque o bien en ellas se percibe de un modo particular la existencia y la providencia de Dios, o bien dichas cosas están dedicadas al nombre divino. Así en Génesis XXXIII, 20 se lee «que Jacob construyó allí

misma naturaleza ha impreso en la mente de todos los hombres unos principios claros, evidentes, los cuales no necesitan de ninguna prueba, sino que más bien de ellos se sacan todos los argumentos, porque en ellos, como en fundamentos firmísimos, estriba la humana ciencia $[\ldots]$ '.

${ }^{27}$ Is 9:6. 
un altar y le puso por nombre "Dios fuerte de Israel"». Ahora bien, Jerónimo lo traduce erróneamente así: «Y tras levantar allí un altar invocó sobre él al fortísimo Dios de Israel» ${ }^{28}$. En efecto esto $\{\ldots\}$ con la verdad del texto. Y en Éxodo XVII dice: «Y construyó Moisés un altar y le puso por nombre Adonái Nisí» ${ }^{29}$. Lo mismo se dice de la ciudad de Jerusalén, en Jeremías XXXIII: «Y éste es el nombre con el que la llamará: "Yahvé nuestra justicia"»". El mismo nombre en el mismo profeta se lee atribuido con el mismo significado al Mesías (XXIII): «Y en sus días estará a salvo Judá, e Israel habitará seguro. Éste será el nombre con el que lo llamará: "Yahvé nuestra justicia"»". Al final de la profecía de Ezequiel XLVIII, 35: «Y el nombre de la ciudad hasta aquel día será: "Yahvé allî"».

El presente trabajo sólo aspira a hacer accesible parte del texto de Moisés Rafael de Aguilar, en la versión intermedia y muy reducida de la traducción latina que esbozó Johann Christoph Wolf. Idealmente estas páginas habrían de constituir un suplemento para una futura edición crítica del texto portugués íntegro, que sería muy deseable que acometiese un experto en la lengua y en la materia.

Recibido: $17 / 05 / 2013$

Aceptado: 11/11/2013

${ }^{28}$ La cita también está en portugués en el original; Wolf reproduce en su lugar el texto de la Vulgata.

${ }^{29}$ Ex 17:15.

${ }^{30}$ Je 33:16.

${ }^{31}$ Je 23:6. 